\title{
COMPARACIÓN DE MÉTODOS CONVENCIONALES Y MOLECULARES PARA LA DETECCIÓN DE Giardia lamblia EN HECES HUMANAS
}

\author{
Edwin Cardona ${ }^{1}$ \\ Silvia Castañeda ${ }^{1}$ \\ María Elena Álvarez ${ }^{2}$ \\ Jorge Enrique Pérez ${ }^{2}$ \\ Fredy Arvey Rivera Páez ${ }^{3}$ \\ Germán Ariel López Gartner ${ }^{4 *}$
}

Recibido el 30 de mayo de 2013 y aprobado el 18 de septiembre de 2013

\section{RESUMEN}

Los protozoarios del género Giardia representan algunos de los parásitos humanos más comunes en el mundo y están entre los principales causantes de infecciones gastrointestinales y enfermedades diarreicas en humanos. La detección del parásito se fundamenta generalmente en los métodos por concentración y microscopía convencional, pero estas técnicas presentan limitaciones por su baja sensibilidad e inespecificidad en el diagnóstico. En procura de mejorar los métodos de diagnóstico, las técnicas moleculares se perfilan como una alternativa promisoria. En este estudio se analizaron 88 muestras de heces provenientes de pacientes de una empresa prestadora de servicios de salud (ASSBASALUD) de la ciudad de Manizales (Caldas). Para la detección de Giardia lamblia en heces se compararon tres métodos diferentes por medio del porcentaje de positividad: los métodos convencionales de concentración de la muestra y observación microscópica, análisis por inmunoensayo (ELISA indirecto) y finalmente la amplificación de dos secuencias génicas nucleares por PCR. Se obtuvieron tres muestras positivas por concentración y microscopía convencional, dos por inmunoensayo y 26 por técnicas moleculares. El estudio sugiere que las pruebas diagnósticas rutinarias basadas en microscopía convencional e inmunoensayo, tienen más bajo porcentaje de detección de este parásito y que esta deficiencia puede ser compensada por medio de la implementación de métodos de diagnóstico molecular basados en PCR, como una estrategia complementaria de apoyo en el diagnóstico de este protozoo.

PALABRAS CLAVE: Giardia lamblia, inmunoensayo, PCR.

\section{COMPARISON OF CONVENTIONAL AND MOLECULAR METHODS FOR DETECTION OF Giardia lamblia IN HUMAN FEACES}

\section{ABSTRACT}

The protozoa of the genus Giardia represent one of the most common human parasites in the world and are among the main causes of gastrointestinal infections and diarrheal diseases in humans. Parasite detection is generally based on concentration and 
conventional microscopy methods, but these techniques have limitations due to their low sensitivity and specificity in diagnosis. In an attempt to improve the diagnostic methods, molecular techniques are emerging as a promising alternative. In this study 88 stool samples from patients of a company that provides health services (ASSBASALUD) in the city of Manizales (Caldas) were analyzed. In order to detect Giardia lamblia in stool, three different methods were compared using the positivity percent: conventional methods for concentration of the sample and microscopic observation, analysis by immunoassay (indirect ELISA) and finally the amplification of two nuclear gene sequences by PCR. Three positive samples were obtained by concentration and conventional microscopy, two by immunoassay and 26 by molecular techniques. The study suggests that routine diagnostic tests based on conventional microscopy and immunoassay have lower detection rate of this parasite and that this deficiency can be compensated by means of the implementation of molecular diagnostic methods based on PCR, as a complementary strategy to support the diagnosis of this protozoan.

\section{KEY WORDS}

Giardia lamblia, immunoassay, PCR.

\section{INTRODUCCIÓN}

Las infecciones por parásitos intestinales constituyen un importante problema de salud pública en todo el mundo por sus altas tasas de prevalencia y amplia distribución mundial, en particular en las regiones tropicales y subtropicales de los países en vía de desarrollo. Se estima que alrededor de 480 millones de personas sufren de amebiasis y otras infecciones causadas por diversos protozoos intestinales, incluyendo a Giardia lamblia, Entamoeba histolytica, Cryptosporidium spp. y Cyclospora cayetanensis, entre otros, que pueden causar diarreas autolimitadas en individuos inmunocompetentes (WHO, 2002; Núñez, 2004).

Los protozoarios del género Giardia son organismos unicelulares binucleados, anaerobios facultativos que infectan la parte superior del intestino delgado de muchas especies de vertebrados, entre ellos el humano. En los países desarrollados y en vía de desarrollo constituyen la causa más frecuente de infección gastrointestinal humana producida por protozoos parásitos, ocasionando infecciones sintomáticas en aproximadamente 200 millones de personas en Asia, África y América Latina, las cuales representan alrededor de 50.000 nuevos casos al año (Yason y Rivera, 2007; Barrientos, Torrico y Suárez, 2008).

El interés por este protista flagelado se ha incrementado a partir de la segunda mitad del siglo $\mathrm{XX}$, al ser reconocido como un patógeno potencial por primera vez en 1962 (Paulino, 2005), debido a que el hospedero infectado elimina el quiste de Giardia al medio ambiente con las heces, y el hospedero susceptible contrae la infección por la ingestión de estos a través de alimentos mal procesados o el agua sin tratamiento adecuado (Fernández y Díaz, 2003; Núñez, 2004). 
Una de las técnicas de referencia más utilizada en los laboratorios para la detección de quistes de Giardia lamblia, es la observación directa bajo el microscopio utilizando el método por concentración o técnica de Ritchie (centrifugación con formol-éter), debido principalmente a su bajo costo y a la sencillez de la prueba. Sin embargo, la identificación por microscopía tradicional requiere tiempo, experiencia, además de ser poco sensible e inespecífica, ya que los quistes pueden confundirse con otros parásitos que presenten morfología semejante (González et al., 1999; Izquierdo et al, 2006).

La aplicación de herramientas moleculares en los estudios de Giardia ha permitido avanzar en el entendimiento de la biología básica de este protozoo. En varias partes del mundo se han incrementado los esfuerzos para desarrollar mejores métodos que permitan detectar Giardia en humanos, en diversos animales y en muestras medioambientales, con miras a prevenir su difusión y a mejorar el diagnóstico para un tratamiento adecuado y oportuno (Cacciò et al., 2003; Corinne, Amar y McLauchlin, 2003; Johnston et al., 2010).

La utilización de técnicas de biología molecular en los estudios de parasitología, ha permitido identificar la especie G. lamblia por medio de la detección de polimorfismos en regiones específicas (loci específicos) y no específicas (Random Amplification of Polymorphic DNA, RAPD) del genoma de esta especie (Corinne et al., 2003; Téllez, et al., 2003; Robertson et al., 2007; Gonçalves et al., 2008). Algunos genes, como los que codifican para la subunidad pequeña ribosomal y otros que codifican ciertas enzimas del metabolismo basal, han demostrado gran especificidad para la caracterización de este parásito (Monis et al., 1999; Cacciò et al., 2003; Téllez et al., 2003; Winkworth et al., 2008).

Teniendo en cuenta que la giardiasis es una enfermedad gastrointestinal de humanos y otros animales, con un impacto socioeconómico importante en todo el mundo, su detección y diagnóstico certero cobran gran importancia para la prevención, vigilancia, control y tratamiento de la enfermedad, especialmente cuando las técnicas microbiológicas convencionales han sido muy limitadas para lograr estos propósitos (Molina et al., 2006).

Varios estudios sobre la prevalencia de la giardiasis en Colombia, indican que esta puede estar en un valor de alrededor del $12 \%$ en la población general y del $28 \%$ entre niños de 1 y 4 años (Chaves et al., 2007; Carmona, Uscátegui y Correa, 2009; Medina et al., 2009). Algunos estudios indican que para 1980 el $81,8 \%$ de las personas en el país se encontraban parasitadas, de éstas el $63 \%$ con parásitos patógenos y $18 \%$ con parásitos no patógenos. Para la zona central colombiana, que incluye el departamento del Quindío, en 1980 se reportó una prevalencia de Giardia lamblia del 13,3\% y en el año 2000 en niños de asentamientos temporales postterremoto se encontró $60,4 \%$, pero se desconoce la frecuencia actual de parasitismo intestinal en la población de niños de guarderías por fuera de estos asentamientos temporales, y su relación con el estado nutricional (Lora-Suárez et al., 2002). 
El objetivo de este estudio es comparar por porcentaje de pruebas positivas tres métodos de diagnóstico de la giardiasis: las técnicas convencionales basadas en concentración y microscopía, las basadas en inmunoensayo enzimático (ELISA) y finalmente aquellas basadas en los análisis moleculares por medio de la amplificación por PCR del gen de la subunidad pequeña ribosomal (SSU-ADNr) y el gen de la enzima triosa fosfato isomerasa (TPI), todas ellas aplicadas a la detección de Giardia lamblia en muestras de materia fecal humana colectadas de pacientes adscritos a un servicio de salud en la ciudad de Manizales (Caldas).

\section{MATERIALES Y MÉTODOS}

En este estudio se analizaron 88 muestras, provenientes de materia fecal de pacientes humanos que consultaron por enfermedad diarreica al servicio de salud de la empresa prestadora de servicios de salud (ASSBASALUD) de la ciudad de Manizales (Caldas), durante los meses de junio a noviembre del año 2010. Las muestras se colectaron en frascos coprológicos estériles, se rotularon y almacenaron bajo refrigeración en neveras de icopor acondicionadas con pilas refrigerantes para garantizar una temperatura de $4^{\circ} \mathrm{C}$, y se transportaron al Laboratorio de Genética de la Universidad de Caldas para su procesamiento. Las muestras se sometieron a tres tipos de análisis. Primero por el método de concentración de Ritchie utilizando formol-éter; luego por inmunoensayo enzimático ELISA (Enzyme-Linked Immuno-Sorbent Assay), mediante el kit comercial Giardia Celisa de CELLABS ${ }^{\circledR}$ y finalmente por amplificación por PCR de dos secuencias génicas nucleares del parásito: gen de la subunidad pequeña ribosomal (SSU-ADNr) y el gen de la enzima triosa fosfato isomerasa (TPI).

\section{Detección de Giardia por concentración (microscopía)}

$1 \mathrm{~g}$ de heces se homogenizó en $7 \mathrm{ml}$ de formalina al 10\% v/v. La mezcla se filtró en gasa y se transfirió a un tubo cónico de centrífuga marca Falcon de $14 \mathrm{ml}$ de capacidad, y se aforó a un volumen de 10 $\mathrm{ml}$ con éter etílico, se homogenizó por inversión y se centrifugó por 4 minutos a $1340 \mathrm{rpm}$. Cuidadosamente se recuperó la capa del sedimento que contenía el concentrado del parásito, y una gota del concentrado se depositó en lámina portaobjetos a la cual se le agregó una gota de lugol parasitológico, luego fue analizada con microscopio óptico utilizando el objetivo de 40X.

\section{Detección de Giardia por inmunoensayo}

Se utilizó el kit comercial para diagnóstico de Giardia Celisa de CELLABS ${ }^{\circledR}$ A, el cual utiliza antígenos de los quistes de Giardia lamblia y anticuerpos monoclonales dirigidos contra dichos antígenos ligados a una placa los 96 pozos. Luego se agrega un anticuerpo policlonal conjugado con peroxidasa la cual al actuar sobre el peróxido de hidrógeno y la 3,3', 5,5'-tetramethylbenzidine (TMB) que actúa como solución cromogénica genera un cambio de color proporcional a la concentración de antígeno presente en la muestra. En el procedimiento se incluyó un control positivo y uno 
negativo, para el primero se añadió una gota del antígeno de Giardia provisto por el fabricante del kit de detección. Para el control negativo se añadieron dos gotas del diluyente, y en los pozos restantes se adicionaron dos gotas del diluyente y una gota de la muestra de materia fecal diluida, se homogenizó y se dejó incubar a temperatura ambiente durante una hora. El contenido de los pozos fue descartado y cada uno se llenó con el buffer de lavado provisto por el fabricante del kit, para garantizar por completo la remoción de moléculas no unidas. Este paso se repitió tres veces. Posteriormente, se añadió el anticuerpo secundario conjugado y se dejó incubar a temperatura ambiente durante 30 minutos. Nuevamente se realizó un lavado con el buffer provisto por el fabricante del kit, se agregó el sustrato con el TMB y se incubó durante 10 minutos a temperatura ambiente en la oscuridad. Se mezcló 2 o 3 veces el contenido de los pozos y se observó la aparición del color azul. Luego de la incubación se agregó a cada pozo una gota de solución de parada, en este procedimiento se generó un cambio de color azul a amarillo cuando los resultados fueron positivos. Por último, se midió la absorbancia en un rango de $450 \mathrm{~nm}$ en el espectrofotómetro Nano Vue (General Electric - serie 110482), según el fabricante del kit, se consideró que una muestra era positiva cuando los valores de la absorbancia fueron $\geq$ de 0,15 . Las muestras fueron analizadas por triplicado en el mismo ensayo.

\section{Detección de Giardia por métodos moleculares de amplificación por PCR}

Se usaron $200 \mu \mathrm{l}$ de la muestra concentrada en tubos de $1,5 \mathrm{ml}$ para realizar una serie de tres lavados con $200 \mu \mathrm{l}$ de agua desionizada y $200 \mu \mathrm{l}$ de buffer salino fosfatado (PBS 1X, pH 7,0), mediante centrifugación a $1500 \mathrm{~g}$ durante 10 minutos. Se realizó la extracción de ADN de las 88 muestras, por el método fenolcloroformo- alcohol isoamílico (25:24:1) (Gonçalves et al., 2008), cada muestra se procesó individualmente en cámara de bioseguridad clase IIA.

Para evitar interferencias en el diagnóstico individual, al iniciar cada jornada de trabajo, se realizó la extracción de una muestra control, libre de parásitos, que permitía corroborar las condiciones del área de trabajo y la pureza de los reactivos. La cantidad y la calidad del ADN extraído, se determinó por electroforesis (Sanguinetti, Días y Simpson, 1994) y también con la ayuda del espectrofotómetro Nano Vue a una absorbancia de 260/280 nanómetros.

Los análisis moleculares correspondieron a la amplificación por PCR de dos secuencias génicas nucleares comúnmente utilizadas como identificadoras del parásito, la subunidad pequeña ribosomal (SSUADNr) y el gen TPI (triosa fosfato isomerasa) (Sulaiman et al., 2003). Se utilizó la técnica de PCR anidada con el fin de maximizar la posibilidad de detección de ADN genómico y con ello incrementar la sensibilidad de la prueba. Para la PCR se usaron cuatro juegos de cebadores, dos para cada uno de los genes: AL4303 - AL4305, AL4304 - AL4306, AL3543 - AL3546 y AL3544 - AL3545 (Tabla 1), la especificidad de cada uno de los cebadores se evaluó con la herramienta "nucleótide blast" disponible en línea (http://blast.ncbi.nlm.nih.govl). 
Tabla 1. Secuencias de los iniciadores de PCR utilizados en las pruebas moleculares.

\begin{tabular}{ll}
\hline Gen e iniciador & Secuencia \\
\hline Gen SSU-ADNr & ATC CGG TCG ATC CTG CCG \\
AL4303 & AGG ATC AGG GTT CGA CT \\
AL4305 & CGG TCG ATC CTG CCG GA \\
AL4304 & GGC GGA GGA TCA GGG T \\
AL4306 & AAA TIA TGC CTG CTC GTC G \\
\hline Gen TPI & CAAACC TTI TCC GCAAAC C \\
AL3543 & CCC TTC ATC GGI G GT AAC TT \\
AL3546 & GTG GCC ACC ACI CCC GTG CC \\
AL3544 & AL3545
\end{tabular}

Los productos de amplificación se separaron en geles de agarosa al $0,6 \%$ bajo condiciones de voltaje constante de $100 \mathrm{~V}$ y coloreados con bromuro de etidio. Para mejorar la resolución de las bandas también se utilizaron geles verticales de poliacrilamida al $6 \%$ coloreados con nitrato de plata (Sanguinetti et al., 1994; Robertson et al., 2007).

\section{RESULTADOS}

Se analizaron en total 88 muestras de materia fecal humana procedentes de pacientes que consultaron con síntomas de enfermedad diarreica a la empresa prestadora de servicios de salud, y se comparó el porcentaje de pruebas positivas mediante tres métodos diagnósticos: concentración (microscopía), inmunoensayo (ELISA) y molecular (PCR de los genes SSU-ADNr y TPI).

Empleando el método convencional de concentración de muestra y microscopía óptica, se pudo comprobar que los quistes de Giardia tenían forma redonda-ovalada con un tamaño aproximado de 8 a 12 micrómetros de diámetro y una coloración citoplásmica ámbar positiva con el reactivo de lugol, lo cual concuerda con la descripción señalada en otros estudios (Beaver, Jung y Cupp, 1984; Adam, 2001; Inpankaew et al., 2007; Molina, 2009). En las placas montadas para microscopía también fue posible observar la presencia de otros microorganismos parasitarios, como por ejemplo Escherichia coli, Entamoeba histolytica y levaduras.

El ADN obtenido mostró buena calidad según el análisis espectrofotométrico. Durante la amplificación de dos genes nucleares por PCR, la mayoría de las muestras positivas exhibieron tamaños acordes con lo reportado en la literatura (Figura 3). Sin embargo, para el gen nuclear SSU-ADNr, amplificado mediante los cebadores AL43 y PCR anidada, en 14 muestras del total analizadas se observaron productos de amplificación cuya estimación está alrededor de $180 \mathrm{pb}$ (Figura 4), lo cual difiere de lo reportado en otros estudios con Giardia para este marcador (Sulaiman et al., 2003). 

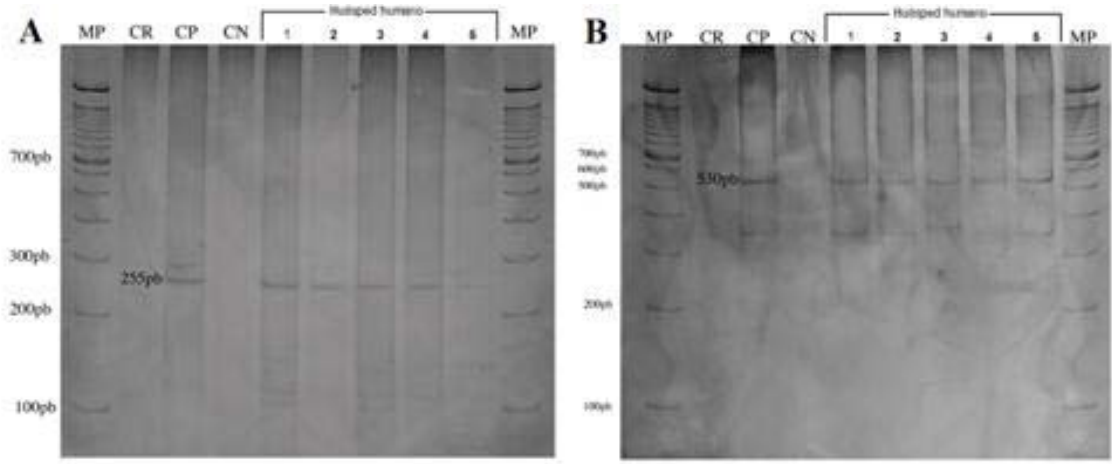

Figura 3. Detección de Giardia lamblia mediante dos marcadores moleculares. A: Productos de PCR anidada con cuatro iniciadores AL43 para la subunidad pequeña ribosomal (SSUADNr). B: Productos de PCR anidada con cuatro iniciadores AL35 para el gen triosa fosfato isomerasa (TPI). En ambos geles los carriles denotan: MP: marcador de peso molecular; CR: control de reacción, $\mathrm{CP}$ : control positivo, $\mathrm{CN}$ : control negativo.

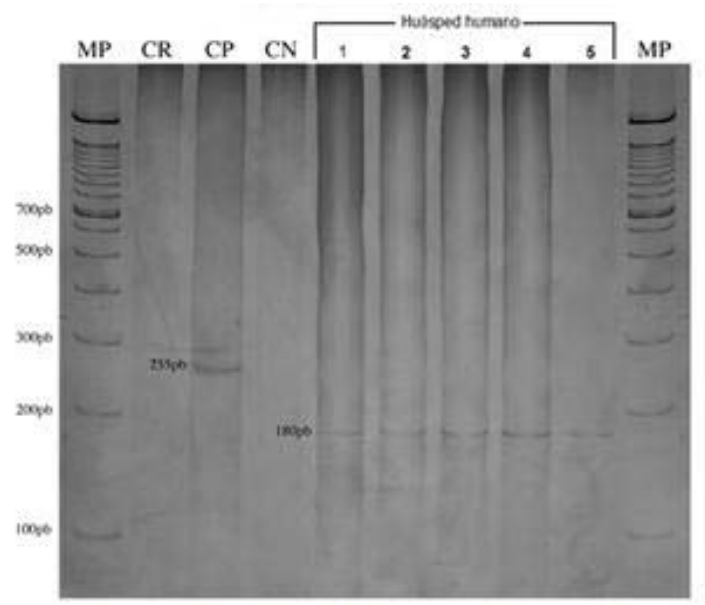

Figura 4. Detección de un alelo de $180 \mathrm{pb}$ para el gen SSU-ADNr. Productos de PCR anidada con cuatro iniciadores AL 43 para la subunidad pequeña ribosomal. Las condiciones de PCR y de electroforesis fueron las mismas en todos los casos a lo largo del estudio. Se aprecia un alelo atípico para este gen con un peso de $180 \mathrm{pb}$ aproximadamente. MP: marcador de peso molecular; $\mathrm{CR}$ : control de reacción, $\mathrm{CP}$ : control positivo, $\mathrm{CN}$ : control negativo. Los carriles numerados del 1 al 5 contienen amplicones procedentes de huéspedes humanos.

Por concentración y microscopía convencional en total se obtuvieron tres muestras positivas para Giardia lamblia (Figura 1). Por el método de inmunoensayo por ELISA se obtuvieron dos muestras positivas (Figura 2). Finalmente, por el método de amplificación génica por PCR de dos loci nucleares del parásito (SSU-ADNr y TPI) se obtuvieron 26 muestras positivas (Figura 3). Los resultados de los tres ensayos se resumen en la Tabla 2. 


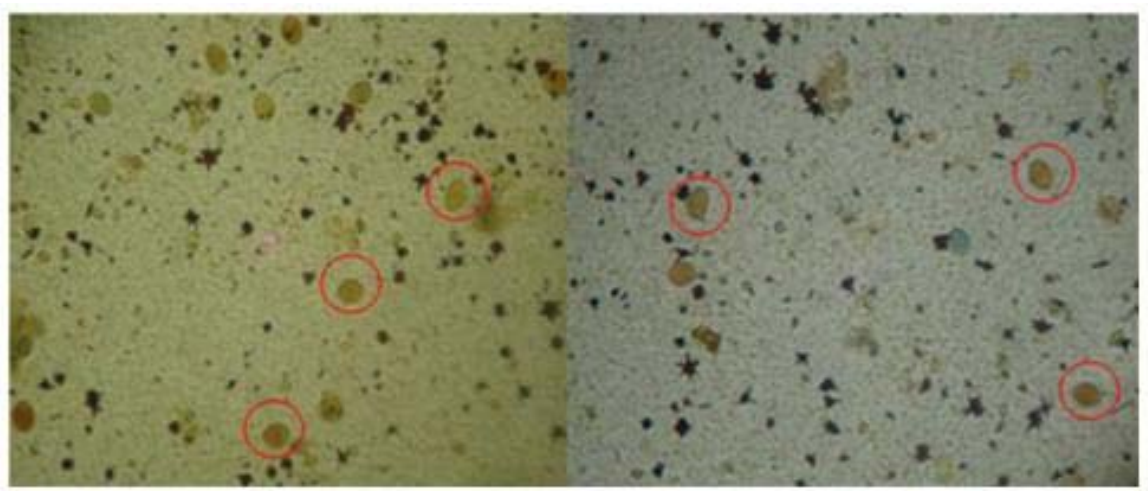

Figura 1. Quistes de Giardia lamblia. Se presentan dos muestras positivas diferentes que proceden del método de concentración. La visualización se realizó con un microscopio óptico convencional utilizando un aumento de $40 \mathrm{X}$. En círculos rojos se señalan algunos parásitos típicos de Giardia lamblia.

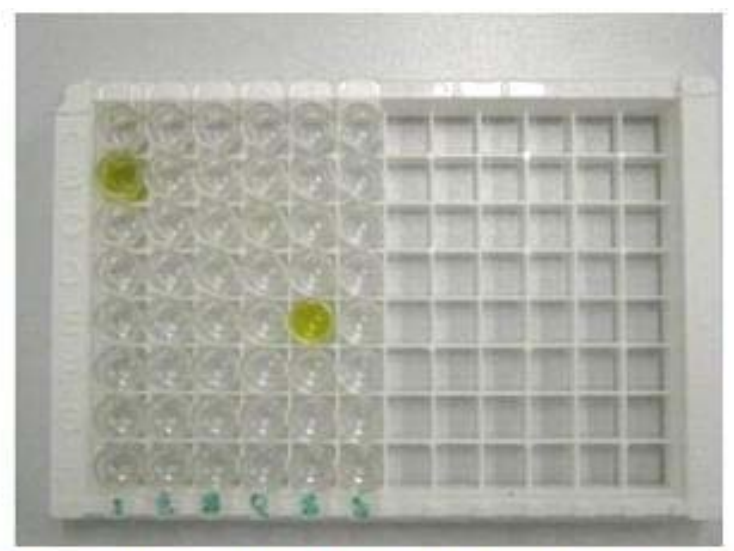

Figura 2. Resultados del inmunoensayo (ELISA) para la detección de Giardia lamblia. EI pozo A1 muestra el control negativo. el pozo B1 muestra el control positivo y el pozo E5 corresponde a una muestra positiva debido a que produce un cambio colorimétrico de azul a amarillo para las muestras positivas.

Las mismas muestras que resultaron positivas por el método convencional de concentración y microscopía, también lo fueron por el de inmunoensayo (ELISA) y por el de amplificación de dos genes nucleares por PCR.

\section{DISCUSIÓN}

Tanto el método convencional de diagnóstico de la giardiasis por concentración de la muestra y microscopía, como el de inmunoensayo por ELISA, presentaron bajo nivel de detección para la detección del parásito en heces humanas, comparados con los métodos moleculares basados en la amplificación por PCR de dos genes marcadores, la subunidad ribosomal pequeña (SSU-ADNr) y la triosa fosfato isomerasa (TPI). Es notablemente mayor el porcentaje de diagnósticos positivos $(29,6 \%$ del total de muestras), comparado con las detecciones logradas por los otros dos métodos; $3,4 \%$ por microscopía convencional y $2,3 \%$ por inmunoensayo tipo ELISA (Tabla 2). 
Tabla 2. Porcentajes de positividad/negatividad de tres métodos de detección de Giardia lamblia

\begin{tabular}{lrr}
\hline \multirow{2}{*}{ Méto do diagnóstico } & \multicolumn{2}{c}{ Muestras* (número y \%) } \\
\cline { 2 - 3 } & Positivas & Negativas \\
\hline Convencional & $3(3,4 \%)$ & $85(96,6 \%)$ \\
Inmunoensayo & $2(2,3 \%)$ & $86(97,7 \%)$ \\
PCR & $26(29,6 \%)$ & $62(70,4 \%)$ \\
\hline
\end{tabular}

- Todas las muestos que resultaron poritivas por los metodos convencionale inmunoensayo, tambien lo fueron por el método de PCR.

Estos resultados se pueden comparar con lo obtenido en otros estudios (Corinne et al., 2003; Braga y Catapani, 2005; Inpankaew et al., 2007; Miller y Sterling, 2007), los cuales reportan que los métodos de observación de quistes al microscopio y el diagnóstico del parásito por la técnica de inmunoensayo por ELISA, fueron menos eficientes comparados con el diagnóstico molecular utilizando amplificación génica por PCR. En el trabajo de Miller y Sterling (2007) los frotis se tiñeron por inmunofluorescencia y los quistes fueron confirmados en tres de las ocho muestras, pero en una cantidad mínima de dos a cuatro quistes por cada una, mientras que por el método molecular se detectó la presencia de Giardia en la totalidad de ellas.

Se debe mencionar que el método de inmunoensayo tiene algunos aspectos que limitan su aplicación, pues requiere de una correcta recolección y conservación de la materia fecal; además, se puede ver afectado por las técnicas de concentración utilizadas y el tiempo transcurrido desde la infección hasta la aparición del parásito en heces, el cual puede ser de dos a tres semanas; por lo que suelen darse falsos negativos en los estadios iniciales de la misma o en el caso de pacientes con patrones de excreción bajos, en los que la detección o confirmación de la infección puede requerir el análisis de dos a tres muestras semanales durante cuatro a cinco semanas.

En los resultados de amplificación por PCR del gen SSU-ADNr se observó que en 14 muestras analizadas existe un producto de amplificación aproximado de $180 \mathrm{pb}$ (Figura 4). Por su parte otro estudio también reportó un producto de amplificación en este gen de tamaño diferente al esperado (Inpankaew et al., 2007). En dicho estudio también se utilizaron los mismos iniciadores AL43 para el gen SSU-ADNr, y el amplicón tenía un tamaño de 300 pb, excediendo hasta en $45 \mathrm{pb}$ lo reportado por los demás autores. Todo esto sugiere, entre otras opciones, la presencia de un biotipo desconocido hasta ahora de Giardia lamblia presente en heces humanas en la población estudiada. Otras opciones incluyen la posibilidad de amplificaciones inespecíficas relacionadas con otros protozoarios asociados a la microbiota humana, como por ejemplo Chilomastix, Entamoeba o Trichomona, entre otros.

Este resultado puede dar lugar a la realización de nuevos estudios, que pueden incluir métodos para la determinación de la sensibilidad y especificidad de las pruebas, incluso a través de la secuenciación de ADN para determinar con mayor precisión las nuevas variantes genéticas que pueden existir en poblaciones humanas poco estudiadas, como es el caso de Manizales. 
Estos hallazgos sugieren que estos marcadores moleculares pueden ser objeto de una variación alélica importante entre aislamientos de la misma especie del parásito, un fenómeno que puede ser aprovechado como una herramienta eficiente para la tipificación molecular de genotipos variables del parásito, la realización de estudios de zoonosis potenciales (de riesgo) y la comprensión de las relaciones que deben existir entre el perfil genético de los aislados, las manifestaciones clínicas y la respuesta a los tratamientos. Todo lo cual conduce a la planeación de mejores estrategias de manejo, control y prevención de la giardiasis y una mejor comprensión de las dinámicas que gobiernan su epidemiología.

\section{AGRADECIMIENTOS}

A las biólogas Margarita Díaz y Carolina Osorio Solano, por su apoyo técnico en laboratorio; a la profesora Carmen Dussan Luber, M.Sc. por la asesoría estadística, y a todos los integrantes del grupo de investigación GEBIOME (Genética, Biodiversidad y Manejo de Ecosistemas) por prestarnos todo el soporte técnico, equipos y entrenamiento requeridos. A la Entidad Promotora de Salud ASSBASALUD, por facilitar la recolección de las muestras para los análisis. Finalmente, a la Vicerrectoría de Investigaciones y Postgrados de la Universidad de Caldas por la financiación del proyecto.

\section{REFERENCIAS}

- Adam, R.D. (2001). Biology of Giardia lamblia. Clinical Microbiol. Reviews, 14, 447-475.

- Barrientos, P.D., Torrico, M.C. y Suárez, E. (2008). Detección de Cryptosporidium spp. y Giardia lamblia en niños inmunodeprimidos del Hospital del Niño Manuel Ascencio Villarroel de Cochabamba en Agosto de 2007. GMB, 31(1), 45-49.

- Beaver, P.C., Jung, R.C, y Cupp, E.W. (1984). Clinical Parasitology (9th ed.). Philadelphia: Lea and Febiger. p. 52-56.

- Braga, A.M. y Catapani, W.R. (2005). Enzyme-linked immunosorbent assay (ELISA) immunoassaying versus microscopy: advantages and drawbacks for diagnosing giardiasis. Sao Paulo Med. J., 123(6), 282285.

- Cacciò, S.M., De Giacomo, M., Aulicino, F.A. y Pozio, E. (2003). Giardia cysts in wastewater treatment plants in Italy. Appl. Environ. Microbiol., 69(6), 3393-3398.

- Carmona, J., Uscátegui , R.M. y Correa, A.M. (2009). Parasitosis intestinal en niños de zonas palúdicas de Antioquia (Colombia). latreia, 22(1), 27-46.

- Chaves, M.P., Fernández, J.A., Ospina, I., López, M.C., Moncada, L. y Reyes, P. (2007). Tendencia de la prevalencia y factores asociados a la infección por Giardia duodenalis en escolares y preescolares de una zona rural de Cundinamarca. Biomédica, 27, 345-351. 
- Corinne, F.L., Amar, P.H. y McLauchlin, J. (2003). Detection and genotyping by real-time PCR/RFLP analyses of Giardia duodenalis from human faeces. J Med Microbiol., 52, 681-683.

- Fernández, P.S. y Díaz, P.S. (2003). Pruebas diagnósticas. Cad Aten Primaria, 10, 120-124.

- Gonçalves, E.M.N., Araújo, R.S., Orban, M., Matté, G.R., Matté, M.H. y Corbett, C.E.P. (2008). Protocol for DNA extraction of Cryptosporidium spp. oocysts in fecal samples. Rev. Inst. Med. trop. S. Paulo, 50(3), 165-167.

- González de la Rosa, J.B., Barbadillo Izquierdo, F., Merino Arribas, J.M. y Sánchez, J. (1999). Aparato Digestivo. Parasitosis intestinales. Protocolo diagnóstico-terapéutico. Bol Pediatr, 39, 106111.

- Inpankaew, T., Traub, R., Thompson, R.C. y Sukthana, Y. (2007). Canine parasitic zoonoses in Bangkok temples. Southeast Asian $\mathrm{J}$ Trop Med Public Health, 38(2), 247-55.

- Izquierdo, A., Mendoza, D., Sarria, C.A. y Álvarez, G. (2006). Prevalencia de Parasitosis Intestinal en niños de nivel primario de la Institución Educativa Juan María Rejas de la localidad Tacneña de Pachía, Perú. Revista Ciencias.com. Recuperado de http://www.ilustrados.com/tema/8809/Prevalencia-ParasitosisIntestinal-ninos-nivel-primario.html

- Johnston, A.R., Gillespie, T.R., Rwego, I.B., McLachlan, T.L., Kent, A.D. y Goldberg, T.L. (2010). Molecular epidemiology of crossspecies Giardia duodenalis transmission in western Uganda. PLOS Negl Trop Dis., 4(5), e683. doi: 10.1371/journal.pntd.0000683.

- Lora-Suárez, F., Marín-Vásquez, C., Loango, N., Gallego, M., Torres, E., González, M., Castaño-Osorio, J. y Gómez-Marín J. (2002). Giardiasis in children living in post-earthquake camps from Armenia (Colombia). BMC Public Health, 2. Recuperado de http://download.springer.com/static/pdf/306/art\%253A10.1186\%2 52F1471-2458-2-

5.pdf?auth66=1385319461_0e96cf4c940760e2af3743cb73a649f3 \&ext=.pdf

- Medina, L., García, M.G., Galván, A.L. y Botero, J. (2009). Prevalencia de parásitos intestinales en niños que asisten al Templo Comedor Sagrado Corazón Teresa Benedicta de la Cruz, del barrio Vallejuelos, Medellín, 2007. latreia, 22(3), 227-234.

- Miller, K.M. y Sterling, C.R. (2007). Sensitivity of Nested PCR in the detection of low numbers of Giardia lamblia cysts. Applied and environmental microbiology, 73(18), 5949-5950.

- Molina, N.B. (2009). Epidemiología molecular de Giardia lamblia en comunidades urbanas y rurales de Buenos Aires y Mendoza, Argentina. (Tesis de Magíster en Ciencias del Laboratorio Clínico). Facultad de Ciencias Exactas. Universidad Nacional de La Plata, Argentina.

- Molina, N.B., Polverino, P., Minvielle, M.C., Apezteguía, M., Aguilar, M. y Basualdo, J.A. (2006). Comparación de métodos de lisis y extracción de ADN de trofozoítos de Giardia lamblia. Parasitol Latinoam, 61, 133-137.

- Monis, P.T., Andrews, R.H., Mayrhofer, G. y Ey, P.L. (1999). Molecular Systematics of the Parasitic Protozoan Giardia intestinalis. Mol Biol Evol., 16(9), 1135-1144.

- Núñez, F.A. (2004). Estudio de factores asociados con la reinfección por Giardia lamblia en niños de círculos infantiles. (Tesis de 
Doctorado). Departamento de Parasitología, Subdirección de Parasitología, Instituto de Medicina Tropical "Pedro Kouri". Cuba.

- Paulino, R.C. (2005). Detección Molecular de Giardia sp. en muestras fecales y agua: Extracción de ADN genómico, PCR y RFLP. (Tesis de Postgrado). Universidad Federal de Paraná, Brasil.

- Robertson, L.J., Forberg, T., Hermansen, L., Hamnes, I.S. y Gjerde, B. (2007). Giardia duodenalis cysts isolated from wild moose and reindeer in norway: genetic characterization by PCR-RFLP and sequence analysis at two genes. J Wildl Dis., 43(4), 576-585.

- Sanguinetti, C., Dias, N. y Simpson, A. (1994). Rapid silver staining and recovery of PCR products separates on polycrylamide gels. Biotechniques, 17, 914-919.

- Sulaiman, I.M., Fayer, R., Bern, C., Gilman, R.H., Trout, J.M., Schantz, P., Das, P., Lal, A.A. y Xiao, L. (2003). Triosephosphate Isomerase Gene Characterization and Potential Zoonotic Transmission of Giardia duodenalis. Enfermedades Infecciosas Emergentes, 9(11), 1444-1452.

- Téllez, A., Winiecka-Krusnell, J., Paniagua, M. y Linder, E. (2003). Antibodies in mother's milk protect children against giardiasis. Scand $\mathrm{J}$ Infect Dis, 35(5), 322-325.

- Winkworth, C.L., Learmonth, J.J., Matthaei, C.D. y Townsend, C.R. (2008). Molecular characterization of Giardia isolates from calves and humans in a region in which dairy farming has recently intensified. Appl Environ Microbiol, 4(16), 5100-5105. doi: 10.1128/AEM.

- World Health Organization. (2002). Guidelines for drinking water quality. Addendum: Microbial agents in drinking water (2nd ed.). Geneva, Switzerland: WHO.

- Yason, J.A. y Rivera, W.L. (2007). Genotyping of Giardia duodenalis isolates among residents of slum area in Manila, Philippines. Parasitol. Res., 101, 681-687.

1. Biólogo Egresado de la Universidad de Caldas.

2. Profesor e investigador del Grupo de Biosalud, Departamento de Ciencias Básicas para la Salud, Facultad de Ciencias para la Salud, Universidad de Caldas.

3. Profesor e investigador del Grupo de investigación Genética, Biodiversidad y Manejo de Ecosistemas, GEBIOME. Departamento de Ciencias Biológicas, Facultad de Ciencias Exactas y Naturales, Universidad de Caldas.

4. Profesor e investigador del Grupo de Investigación en Tecnologías de Información y Redes, GITIR. Departamento de Sistemas e Informática, Facultad de Ingeniería, Universidad de Caldas.

* Autor para la correspondencia.

Para citar este artículo: Cardona, E., Castañeda, S., Álvarez, M. E., Pérez, J. E., Rivera Páez, F. A. \& López Gartner, G. A. (2014). Comparación de métodos convencionales y moleculares para la detección de Giardia lamblia en heces humanas. Revista Luna Azul, 38, 159-170. Recuperado de http://lunazul.ucaldas.edu.co/index.php?option=content\&task=v iew\&id $=900$ 